Revista Eletrônica da Faculdade de Direito da Universidade Federal de Pelotas (UFPel)

Dossiê Consumo e Vulnerabilidade: a proteção jurídica dos consumidores no século

XXI. Vol. 03, N. 1, Jan-Jun., 2017.

ISSN - 2448-3303

\title{
ALIMENTOS COM GLÚTEN E INFORMAÇÃO AOS CONSUMIDORES: A RELAÇÃO ENTRE O PRINCÍPIO DA INFORMAÇÃO DO CÓDIGO DE DEFESA DO CONSUMIDOR E A LEI N ${ }^{\circ} \mathbf{1 0 . 6 7 4 / 0 3 . ~}$
}

\section{LETÍCIA FRANCIELLY LORENA ${ }^{1}$}

\section{Resumo:}

O Código de Defesa do Consumidor, baseado em princípios como o da informação e da transparência, possibilita que direitos fundamentais resguardados pela Constituição Federal do Brasil sejam efetivamente respeitados, garantindo qualidade de vida a todos os membros da sociedade e proporcionando uma vida digna, bem-estar social e condições para o desenvolvimento de potencialidades dos seres humanos, independente de suas particularidades. Nesta perspectiva, a Lei n. 10.674/03 busca aumentar a proteção jurídica dos portadores da Doença Celíaca nas relações de consumo frente aos fornecedores, no que tange a informação de rótulos e embalagens.

Palavras Chaves: princípio da informação, código de defesa do consumidor, lei do glúten

\begin{abstract}
The consumer protection based on information and transparency principles allow fundamental rights to be guaranteed by the Brazilian Federal Constitution, guaranteeing life quality for all society members and giving fair life conditions, social well-being and conditions to develop human beings potential, no matter what. In this perspective, Law number 10.674/03 seeks to increase the legal protection with celiac disease bearers in the consumption relation within the distributors regarding labels and packaging.
\end{abstract}

Keywords: principle of information, law of consumption protection

\footnotetext{
1 Acadêmica da Universidade Federal de Pelotas, membro do Grupo de Estudos e Pesquisa em Direito do Consumidor (GECON).
} 


\section{Revista Eletrônica da Faculdade de Direito da Universidade Federal de Pelotas (UFPel) Dossiê Consumo e Vulnerabilidade: a proteção jurídica dos consumidores no século XXI. Vol. 03, N. 1, Jan-Jun., 2017.}

ISSN - 2448-3303

Sumário: 1. Introdução - 2. Princípio da Informação no Código de Defesa do Consumidor - 3. Glúten e Doença Celíaca - 4. Lei n 10.674/03 - Lei do Glúten - 5. Conclusões - 6. Referências bibliográficas.

\section{1) Introdução}

Com o advento da Revolução Industrial, a população que era predominantemente rural passou a se deslocar para as cidades com a finalidade de trabalhar nas fábricas. Entre as inúmeras mudanças que ocorreram na sociedade neste período, uma delas foi o desenvolvimento dos alimentos industrializados e embalados, os quais tinham uma durabilidade maior que os anteriormente comercializados, que eram de consumo imediato.

Tais alimentos logo se difundiram na sociedade, uma vez que as pessoas não tinham mais os espaços rurais para se dedicar ao cultivo de alimentos, além do fato de que não tinham mais o tempo necessário para produzir, uma vez que estavam ocupados, muitas vezes, exercendo sua nova profissão - a de operário.

Atualmente, a maior parte dos alimentos consumidos é industrializada, sendo as embalagens os veículos de comunicação entre o fornecedor e o consumidor, uma vez que é possível encontrar nelas, as embalagens, informações acerca dos nutrientes presentes nos alimentos.

O Código de Defesa do Consumidor busca resguardar os direitos do pólo mais vulnerável da relação jurídica de consumo, o consumidor, visando, por exemplo, regularizar e padronizar as informações das embalagens de produtos industrializados.

O que o diploma legal supramencionado faz vai de encontro com a Carta Magna Brasileira, uma vez que esta estabelece direitos como os da informação, saúde, alimentação/ alimentação adequada e soberania alimentar no rol dos direitos fundamentais.

Tais direitos estão embasados em princípios como o da igualdade, liberdade, dignidade da pessoa humana, informação, transparência, boa-fé, entre outros.

No Brasil, existem inúmeras pessoas com particularidades alimentares, como os portadores da Doença Celíaca, os quais não podem consumir alimentos com glúten. Estes indivíduos, 


\section{Revista Eletrônica da Faculdade de Direito da Universidade Federal de Pelotas (UFPel) Dossiê Consumo e Vulnerabilidade: a proteção jurídica dos consumidores no século XXI. Vol. 03, N. 1, Jan-Jun., 2017.}

ISSN - 2448-3303

denominados celíacos, dependem da informação dos rótulos dos alimentos, uma vez que a forma de tratamento para esta patologia é basicamente uma dieta restrita ao glúten.

Diante da necessidade de resguardar os direitos dos celíacos, a legislação pertinente, Lei n. 10.674/03, obrigou aos fornecedores a colocar a expressão "contém glúten" e "não contém glúten" nos rótulos e embalagens.

Este artigo busca demonstrar a importância do principio da informação presente no Código de Defesa do Consumidor em conjuntura com a Lei do Glúten, Lei n. 10.674/03, no que tange a proteção a saúde dos portadores da Doença Celíaca.

\section{2) Princípio da Informação no Código de Defesa do Consumidor}

O Código de Defesa do Consumidor tem como objetivo proteger o pólo hipossuficiente das relações de consumo, no caso, o consumidor, uma vez que ele é considerado a parte mais vulnerável do elo econômico.

Paulo Valério Dal Pai Moraes (2001, p.96) conceitua vulnerabilidade nos seguintes moldes:

\footnotetext{
Vulnerabilidade é, então, o principio pelo qual o sistema jurídico positivado brasileiro reconhece a qualidade daquele ou daqueles sujeitos mais fracos na relação de consumo, tendo em vista a possibilidade de quem venham a ser ofendidos ou feridos, na sua incolumidade física ou psíquica, bem como no âmbito econômico, por parte do sujeito mais potente da mesma relação.
}

Esta vulnerabilidade do consumidor é o ponto fundamental do CDC e, segundo a professora Claudia Lima Marques (2008), ela pode ser oriunda de características: técnica, jurídica, fática e/ou informacional do produto/serviço. Ou seja, o usuário pode não ter conhecimento científico sobre o bem adquirido ou o serviço contratado, bem como, pode não compreender as conseqüências jurídicas ao firmar um contrato ou comprar um bem. Em relação à informação, o consumidor pode não dispor delas por falha do fornecedor ou pode ter acesso a elas de forma excessiva e desordenada, gerando confusão e ate mesmo certa manipulação do consumidor por parte do fornecedor.

Cabe ressaltar que o CDC não busca proteger o consumidor dando-lhe sempre razão frente ao fornecedor, mas visa gerar uma harmonização, ou seja, um equilíbrio entre os personagens da relação jurídica, garantindo a igualdade na hora de contratar. 


\section{Revista Eletrônica da Faculdade de Direito da Universidade Federal de Pelotas (UFPel) Dossiê Consumo e Vulnerabilidade: a proteção jurídica dos consumidores no século XXI. Vol. 03, N. 1, Jan-Jun., 2017.}

ISSN - 2448-3303

Diante de uma sociedade moderna e globalizada, sedenta por rápidas relações de consumo, os contratos de adesão ocupam cada vez mais lugar nas atividades rotineiras humanas. Mesmo estes, onde existem cláusulas impositivas, bem como os contratos elaborados em conjunto por ambas as partes contratantes são resguardadas pelo diploma legal em questão.

O CDC em seu Capitulo III, trata sobre os direitos básicos do consumidor, sendo o Art. $6^{\circ}$, III, o que se refere diretamente ao princípio da informação, vejamos:

\footnotetext{
Art. $6^{\circ}$ São direitos básicos do consumidor:

(...)

III - a informação adequada e clara sobre os diferentes produtos e serviços, com especificação correta de quantidade, características, composição, qualidade, tributos incidentes e preço, bem como sobre os riscos que apresentem.
}

A sociedade precisa saber o que esta consumindo, sua escolha deve ser consciente, ela tem o direito de ser informada e o fornecedor tem o dever de informar, criando assim uma ligação mais honesta no mercado de consumo.

Segundo Paulo Luiz Netto Lobo (2001) o dever de informar origina-se do princípio da boa-fé, da conduta baseada na lealdade, probidade, confiança, correção e na ausência de qualquer vontade de prejudicar o outro.

O princípio da informação está diretamente relacionado ao princípio da transparência (Art. $4^{\circ}, \mathrm{CDC}$ ), haja vista que ambos são deveres dos prestadores de serviços e são princípios responsáveis por nortear o Código de Defesa do Consumidor.

Segundo Fabio Ulhoa Coelho (1996), de acordo com o princípio da transparência, não basta ao empresário abster-se de falsear a verdade, deve ele transmitir ao consumidor em potencial todas as informações indispensáveis à decisão de consumir ou não o fornecimento.

Tais princípios, o da informação e o da transparência, são importantes para que consumidor tenha autonomia e liberdade para escolher conscientemente determinado produto ou prestação de serviço, diante de uma gama de opções ofertadas pelos fornecedores.

O Ministro do Superior Tribunal de Justiça, Antônio Herman V. Benjamin, destaca a importância do direito à informação, no Recurso Especial no 586.316/MG:

(...) A informação é irmã-gêmea - 'inseparável', diz Jorge Mosset Iturraspe (Defensa Del Consumidor, $2^{\mathrm{a}}$ ed., Santa fé, Rubinza 1 - Culzoni, 200 3, p. 29) dos Princípios da Transparência, da Confiança e da Boa-fé Obje • va. Sem ela, esses princípios não se realizam. Por isso se apregoa que ser informado é ser livre, inexistindo plena liberdade sem informação. Perceptível, então, a contradição entre aqueles que pregam o 'livre 


\section{Revista Eletrônica da Faculdade de Direito da Universidade Federal de Pelotas (UFPel) Dossiê Consumo e Vulnerabilidade: a proteção jurídica dos consumidores no século XXI. Vol. 03, N. 1, Jan-Jun., 2017.}

ISSN - 2448-3303

mercado' e, ao mesmo tempo, negam, solapam ou inviabilizam a plena informação ao consumidor. Segundo, é a informação que confere ao consumidor 'a possibilidade de utilizar os produtos comercializados com plena segurança e de modo satisfatório aos seus interesses' (Gabriel A. Stilitz Protección Jurídica Del Consumidor, Buenos Aires, Depalma, 1986, p. 45). Só o consumidor bem informado consegue de fato usufruir integralmente os benefícios econômicos que o produto ou serviço lhe proporciona, bem como proteger-se de maneira adequada dos riscos que apresentam. Por esse último aspecto (proteção contra riscos), a obrigação de informar deriva da obrigação de segurança, que modernamente, por força de lei ou da razão, se põe como pressuposto para o exercício de qualquer atividade no mercado de consumo (...).

Existem duas fases da informação no mercado de consumo classificadas como précontratual e contratual. A primeira é vista como um meio destinado a dar ao consumidor informações que possibilitem uma manifestação livre e consciente de sua vontade. São, via de regra, informações sobre o próprio produto ou serviço. A segunda tem como objetivo evitar a ocorrência de danos ou prejuízos superiores aos previstos no contrato. Ela trata, sobretudo, das condições formais em que a manifestação de vontade tem lugar (BENJAMIN, 2008).

O presente artigo aborda, sobretudo, a informação pré-contratual, uma vez que é nessa fase que o consumidor toma a decisão de adquirir ou não o bem ou o serviço

Alexandre David Malfatti (2003, pg. 236), sobre o direito de informar, declara:

O fornecedor tem o direito de informar, compreende-se aqui o direito de comunicar-se com o consumidor de forma a colocar os produtos ou serviços, no mercado de consumo. $\mathrm{O}$ direito de informação do fornecedor insere-se dentro das diversas ferramentas do marketing: embalagem, publicidade, atendimento ao consumidor (centrais ou serviços de atendimento), etc. Ao fornecedor, como regra, não deve ser tolhido o exercício do direito de informar previsto na Lei n. 8.078/90, principalmente quando sua finalidade é propiciar a melhoria do mercado de consumo.

O Código de Defesa do Consumidor, em seu Art. 31, também fez alusão ao direito de informação ao declarar que a oferta e apresentação de produtos ou serviços devem assegurar informações corretas, claras, precisas, ostensivas e em língua portuguesa sobre suas características, qualidades, quantidade, composição, preço, garantia, prazos de validade e origem, entre outros dados, bem como sobre os riscos que apresentam à saúde e à segurança dos consumidores.

A informação deve ser compreendida, entendida e assimilada pelo consumidor menos instruído. $\mathrm{O}$ fornecedor deve ser claro ao demonstrar os potenciais de riscos à saúde e à segurança que determinado produto ou serviço pode causar ao consumidor, sob pena de responsabilização. 


\section{Revista Eletrônica da Faculdade de Direito da Universidade Federal de Pelotas (UFPel) Dossiê Consumo e Vulnerabilidade: a proteção jurídica dos consumidores no século XXI. Vol. 03, N. 1, Jan-Jun., 2017.}

ISSN - 2448-3303

\section{3) Glúten e Doença Celíaca}

O glúten é uma proteína presente naturalmente em alguns cereais, como o trigo, cevada e centeio. A palavra vem do latim glúten, que significa cola. Este conceito está ligado à função desta proteína que é a de gerar a viscosidade e elasticidade ao alimento.

Existem pessoas que apresentam uma hipersensibilidade ao glúten, elas podem ser alérgicas ou intolerantes. Nestes indivíduos o glúten impede uma digestão normal, pois ele provoca danos na mucosa do intestino delgado. Uma dieta balanceada, sem a presença de alimentos que contenham glúten, permite que o indivíduo tenha uma vida normal e de qualidade.

Muitas pessoas pensam que alergia e intolerância alimentar são a mesma coisa. No entanto, embora os sintomas apresentados sejam semelhantes e, nos dois casos, o problema possa ser de nascença ou adquirido ao longo da vida, as causas de uma e de outra são diferentes (IDEC, 2013b).

"A intolerância é a incapacidade de digerir determinados alimentos ou aditivos alimentares pela falta de alguma enzima necessária para completar a digestão. Com o passar dos anos, as enzimas podem se tornar ineficientes, o que explica os casos de intolerância adquirida", informa Paula Canavó, nutricionista do Hospital Alemão Oswaldo Cruz, de São Paulo (SP). Já a alergia envolve mecanismos imunológicos. "Trata-se de manifestações resultantes das reações do organismo contra alérgenos, isto é, substâncias estranhas ao seu funcionamento, que podem ser alimentos, toxinas, fungos, aditivos alimentares, entre outros", esclarece (IDEC, 2013b).

Segundo a FENACELBRA, Federação Nacional das Associações de Celíacos do Brasil, os sintomas mais comuns da doença são: diarréia crônica, prisão de ventre, anemia, falta de apetite, vômitos, emagrecimento/ obesidade, atraso no crescimento, humor alterado (irritabilidade/ desanimo), distensão abdominal, dor abdominal, aftas de repetição e osteoporose/ osteopenia.

O tratamento indicado para pessoas portadoras da doença celíaca, classificados como celíacos, é uma alimentação restritiva, ou seja, sem glúten, durante toda a vida, uma vez que qualquer quantidade consumida, mínima que seja, pode ser prejudicial ao celíaco. Ainda não foram descobertos medicamentos que previnam os danos ou que evitem a reação do intestino à presença do glúten.

Após o tratamento mediante dieta restrita ao glúten, muitas pessoas tendem a melhorar e, em alguns casos, os sintomas podem ate mesmo desaparecer. Porém há pacientes que mesmo com 


\section{Revista Eletrônica da Faculdade de Direito da Universidade Federal de Pelotas (UFPel) Dossiê Consumo e Vulnerabilidade: a proteção jurídica dos consumidores no século XXI. Vol. 03, N. 1, Jan-Jun., 2017.}

ISSN - 2448-3303

o tratamento correto não observam melhora porque a patologia está presente há muito tempo no seu organismo.

Existem evidências que a patologia em questão esteja associada com fatores genéticos complexos e uma resposta imunológica anormal a antígenos de cereais ingeridos. Portanto, pessoas com histórico familiar da doença possuem mais chances de desenvolvê-la. (HAMILTON; FARBER; RUBIN, 2002).

Entre o grupo com maior predisposição podemos encontrar os pacientes portadores de diabetes do tipo 2, portadores de Síndrome de Down, de dermatite herpetiforme, pacientes com doença autoimune da tireóide, casais inférteis, crianças anêmicas, ou adultos com anemiaferroprina, fadiga persistente (BELL, 2005).

Segundo J. Joseph Connon (2003), a doença celíaca é extremamente rara entre negros, japoneses e chineses, e predomina entre os adultos, sobretudo mulheres na idade reprodutiva.

Segundo a FENACELBRA $1 \%$ da população mundial tem doença celíaca. No Brasil, estima-se que cerca de dois milhões de brasileiros são acometidos pela patologia causada pela intolerância ao glúten, mas muitos não sabem uma vez que o diagnóstico do problema é difícil e ele pode ser confundido com doenças do intestino ou relacionado à carência de nutrientes.

Diante da complexidade da Doença Celíaca e de seu tratamento ser baseado unicamente em restrição alimentar, o direito viu como necessário a proteção dessas pessoas, uma vez que nossa Constituição esta embasada em princípios como a da dignidade da pessoa humana e do direito à alimentação saudável.

A Lei n. 10.674/03, buscando a melhoria na qualidade de vida dos celíacos, tornou obrigatória a presença da expressão "contém glúten" ou "não contém glúten" na embalagem dos alimentos industrializados. Ela vem de encontro com uma política mundial de proteção ao doente celíaco.

\section{4) Lei n. 10.674/03 - Lei do Glúten}

A primeira lei que abordou a proteção do portador de Doença Celíaca no Brasil foi a Lei n. 8.543, de 23 de dezembro de 1992. Ela determinava a impressão de advertência em rótulos e embalagens de alimentos industrializados que contivessem glúten, a fim de evitar o consumo por 


\section{Revista Eletrônica da Faculdade de Direito da Universidade Federal de Pelotas (UFPel) Dossiê Consumo e Vulnerabilidade: a proteção jurídica dos consumidores no século XXI. Vol. 03, N. 1, Jan-Jun., 2017.}

ISSN - 2448-3303

parte de portadores da doença celíaca ou síndrome celíaca. A informação tinha que ser nítida e em destaque, para facilitar a leitura.

Em 16 de maio de 2003, a lei supracitada foi ab-rogada pela Lei n. 10.674, a qual aumentou a proteção ao direito de informação, pois obrigou os fornecedores a rotularem as embalagens com a expressão "contém glúten” ou "não contém glúten".

Dispõe a Lei n 10.674/03:

Art. $1^{\mathrm{o}}$ Todos os alimentos industrializados deverão conter em seu rótulo e bula, obrigatoriamente, as inscrições "contém Glúten" ou "não contém Glúten", conforme o caso.

$\S 1^{\underline{0}}$ A advertência deve ser impressa nos rótulos e embalagens dos produtos respectivos assim como em cartazes e materiais de divulgação em caracteres com destaque, nítidos e de fácil leitura.

$\S 2^{\mathrm{o}}$ As indústrias alimentícias ligadas ao setor terão o prazo de um ano, a contar da publicação desta Lei, para tomar as medidas necessárias ao seu cumprimento.

A Agência Nacional de Vigilância Sanitária (ANVISA) é o órgão responsável pela elaboração e fiscalização das regulamentações sobre rotulagem de embalagens, contudo, outros órgãos também podem regular sobre a matéria, como por exemplo, o Ministério da Agricultura, Pecuária e Abastecimento (MAPA), o Ministério da Justiça e até mesmo o Congresso Nacional.

A Resolução n. 259/2002 da ANVISA declara que:

Rotulagem: É toda inscrição, legenda, imagem ou toda matéria descritiva ou gráfica, escrita, impressa, estampada, gravada, gravada em relevo ou litografada ou colada sobre a embalagem do alimento.

Embalagem: É o recipiente, o pacote ou a embalagem destinada a garantir a conservação e facilitar o transporte e manuseio dos alimentos.

O rótulo é o primeiro contato entre o produto e consumidor, ou seja, ele é a identidade do produto, é o meio utilizado pelo fabricante para indicar a composição do alimento, listando os ingredientes, a quantidade, o prazo de validade, informação nutricional, nome e endereço do fabricante, número de Serviço de Inspeção Federal, método de conservação, entre outros dados.

Dispõe também a Resolução n. 259/2002 sobre os princípios gerais da rotulagem:

Os alimentos embalados não devem ser descritos ou apresentar rótulo que:

a) utilize vocábulos, sinais, denominações, símbolos, emblemas, ilustrações ou outras representações gráficas que possam tornar a informação falsa, incorreta, insuficiente, ou que possa induzir o consumidor a equívoco, erro, confusão ou engano, em relação à verdadeira natureza, composição, procedência, tipo, qualidade, quantidade, validade, rendimento ou forma de uso do alimento; 


\section{Revista Eletrônica da Faculdade de Direito da Universidade Federal de Pelotas (UFPel) Dossiê Consumo e Vulnerabilidade: a proteção jurídica dos consumidores no século XXI. Vol. 03, N. 1, Jan-Jun., 2017.}

ISSN - 2448-3303

b) atribua efeitos ou propriedades que não possuam ou não possam ser demonstradas;

c) destaque a presença ou ausência de componentes que sejam intrínsecos ou próprios de alimentos de igual natureza, exceto nos casos previstos em Regulamentos Técnicos específicos;

d) ressalte, em certos tipos de alimentos processados, a presença de componentes que sejam adicionados como ingredientes em todos os alimentos com tecnologia de fabricação semelhante;

e) ressalte qualidades que possam induzir a engano com relação a reais ou supostas propriedades terapêuticas que alguns componentes ou ingredientes tenham ou possam ter quando consumidos em quantidades diferentes daquelas que se encontram no alimento ou quando consumidos sob forma farmacêutica;

f) indique que o alimento possui propriedades medicinais ou terapêuticas;

g) aconselhe seu consumo como estimulante, para melhorar a saúde, para prevenir doenças ou com ação curativa.

A obrigação de informar estipulada pela lei em comento apenas estabelece que determinado produto declare a presença ou não de glúten, ela não trata sobre os riscos oferecidos no consumo. Não há qualquer advertência ao consumidor.

A ausência de advertência fere com o estabelecido pelo Código de Defesa do Consumidor, em seu Art. 31, o qual declara que a informação deve ser clara e precisa. O Art. $9^{\circ}$, do CDC, também é ferido, uma vez que ele estabelece que no caso de produtos ou serviços potencialmente nocivos ou que ofereçam perigos a saúde ou segurança dos consumidores, ficam os fornecedores obrigados a informar, ostensiva e adequadamente, a respeito da sua periculosidade ou nocividade.

A falta de informação mais aprofundada interfere na eficácia da Lei do Glúten, uma vez que a legislação busca proteger o celíaco, mas alguns dados relevantes acerca do produto são muitas vezes suprimidos.

A Lei n. 10.674/03 apresenta lacunas, uma vez que apenas conter a expressão "contém glúten" e "não contém glúten" é insuficiente para proteger os celíacos, uma vez que não esclarece sobre os riscos do consumo de alimento com glúten ao portador da Doença Celíaca.

O Código de Defesa do Consumidor busca preencher tais lacunas, porém quando não consegue pode ocorrer a responsabilização do fornecedor pelos defeitos de informação que possam ser encontrados.

\section{Conclusões}

Diante do exposto, podemos concluir que a Lei n. 10.764/03 foi um avanço legislativo no que tange a proteção de pessoas com particularidades alimentar, porém nota-se que ela é insuficiente, uma vez que a presença da informação "contém glúten" ou "não contém glúten" não 


\section{Revista Eletrônica da Faculdade de Direito da Universidade Federal de Pelotas (UFPel) Dossiê Consumo e Vulnerabilidade: a proteção jurídica dos consumidores no século XXI. Vol. 03, N. 1, Jan-Jun., 2017.}

ISSN - 2448-3303

adverte os consumidores sobre os riscos do consumo do alimento e as conseqüências que serão ocasionadas aos portadores da Doença Celíaca.

O Código de Defesa do Consumidor, em diapasão com a Constituição Federal, baseado no principio da informação e da transparência busca preencher as lacunas existentes na rotulagem de alimentos com glúten, uma vez que cria requisitos a serem cumpridos como a informação ser adequada e clara sobre o produto e a especificação sobre quantidade, características, composição, qualidade, garantia, prazo de validade entre outros.

Diante de uma legislação clara como o CDC, os fornecedores de alimentos industrializados que não estiverem de acordo com as regras estabelecidas podem ser responsabilizados pela via administrativa, civil ou penal.

O que a Constituição Federal, o Código de Defesa do Consumidor e a Lei do Glúten buscam é garantir o direito da dignidade da pessoa humana e da alimentação adequada aos portadores da Doença Celíaca, fazendo com que estes estejam sempre informados e conscientes dos produtos que irão consumir, não expondo sua saúde a risco e gerando assim melhor qualidade de vida.

6) Referências

\subsection{Bibliográficas}

BELL, Martin. Doença Celíaca: diagnostico e tratamento. Medical Update. São Paulo, v. 3, n. 21, p. 27-31, mar./abr.2005

BENJAMIN, Antonio Herman de Vasconcellos e. Das praticas comerciais. In: GRINOVER, Ada Pelegrini. Et al. Código de Defesa do Consumidor: comentado pelos autores do anteprojeto. Rio de Janeiro: Forense Universitária, 2007, p. 251-503.

BESSA, Leonardo Roscoe; MOURA, Walter Jose Faiad de; SILVA, Juliana Pereira da (Coord). Manual de Direito do Consumidor. 4. ed. Brasília : Escola Nacional de Defesa do Consumidor, 2014. 290 p.

COELHO, Fábio Ulhoa. O crédito ao consumidor e a estabilização da economia, Revista da Escola Paulista de Magistratura, 1/96, set./dez. 1996

CONNON, J. Joseph. Doença Celíaca. In: SHILS, Maurice E. (Coord). Et al. Tratado de Nutrição moderna na saúde e na doença. 9 ed. São Paulo: Manole, 2003. p. 1243-1248.

HAMILTON, R. Stanley; FARBER, L. John; RUBIN, Emanuel. O Tratado Gastrointestinal. In: RUBIN, Emanuel (Org.); FABER, John L. (Org). Patologia, 3 ed. Rio de Janeiro: Guanaraba Koogan, 2002, p. 650-730.

LOBO, Paulo Luiz Netto. A informação como direito fundamental do consumidor. Revista de Direito do Consumidor. São Paulo, v. 10, n. 37, p. 59-76, jan./mar.2001. 


\section{Revista Eletrônica da Faculdade de Direito da Universidade Federal de Pelotas (UFPel) Dossiê Consumo e Vulnerabilidade: a proteção jurídica dos consumidores no século XXI. Vol. 03, N. 1, Jan-Jun., 2017.}

ISSN - 2448-3303

MALFATTI, Alexandre David. O direito de informação no Código de Defesa do Consumidor. São Paulo: Alfabeto Juridico, 2003.

MARQUES, Claudia Lima. Superação das Antinomias pelo diálogo das fontes: modelo brasileiro de coexistência entre o Código de Defesa do Consumidor e o Código Civil de 2002. Revista de Direito do Consumidor. São Paulo, v. 13, n. 51, p. 34-67, jul./set.2004.

MORAES, Paulo Valério Dal Pai, Código de Defesa do Consumidor: no contrato, na publicidade, nas demais práticas comerciais. 2 ed. Porto Alegre: Sintese, 2001.

\subsection{Sítios}

ANVISA, RDC n. 259/2002. Brasilia, 2002. Disponivel em: <http://portal.anvisa.gov.br/documents/10181/2718376/RDC_259_2002_COMP.pdf/9c816a4d2dc7-48bf-80e4-e8891f640cf2 > Acesso em: 27.maio.2017

FENACELBRA. Doença Celíaca - DC. Disponivel em: < http://www.fenacelbra.com.br/fenacelbra/doenca-celiaca/>. Acesso em: 06.maio.2017.

Lei n. 8.543, de 23 de dezembro de 1992. Determina a impressão de advertências em rótulos e embalagens de alimentos industrializados que contenham glúten, a fim de evitar a doença celíaca ou síndrome celíaca. Brasilia: 1992. Disponivel em <http://www.planalto.gov.br> Acesso em: 05.mai.2017

Lei n. 10.674, de 16 de maio de 2003. Obriga a que os produtos alimentícios comercializados informem sobre a presença de glúten, como medida preventiva e de controle da doença celíaca. Brasília: 2003. Disponível em: <http://www.planalto.gov.br>. Acesso em: 05.mai.2017

SUPERIOR TRIBUNAL DE JUSTICA, Resp 586.316/MG. $2^{\text {a }}$ Turma Civ. Rel. Ministro Herman Benjamin, J. 17/04/07. Disponível em <http://www.stj.jus.br> Acesso em: 15.mai.2017 $<$ http://www.direitonet.com.br/artigos/exibir/9154/Principio-da-informacao-do-Codigo-de-Defesado-Consumidor> Acesso em 06.mai.2017

<http://www.ambito-juridico.com.br/site/index.php?n_link=revista_artigos_leitura\&artigo_id=5963> Acesso em: 06.mai.2017

<https://pt.wikipedia.org/wiki/Gl\%C3\%BAten> Acesso em: 15.mai.2017

$<$ http://www.mobilizadores.org.br/wp-content/uploads/2015/04/Cartilha-Rotulagem-de-

Alimentos_Avancos-e-Desafios_CNPq.pdf > Acesso em: 27.mai.2017 